\title{
Chronic Deep Cerebellar Stimulation Promotes Long-Term Potentiation, Microstructural Plasticity, and Reorganization of Perilesional Cortical Representation in a Rodent Model
}

\author{
Jessica Cooperrider, ${ }^{1,2 *}$ Havan Furmaga, ${ }^{1,2 *}$ Ela Plow, ${ }^{1,3}{ }^{\oplus}$ Hyun-Joo Park, ${ }^{2}{ }^{\circ}$ Zhihong Chen, ${ }^{2}$ Grahame Kidd, ${ }^{2}$ \\ (iD) Kenneth B. Baker, ${ }^{4}$ (D) John T. Gale, ${ }^{1,2}$ and (i) Andre G. Machado ${ }^{1,2,3}$ \\ ${ }^{1}$ Center for Neurological Restoration, Neurological Institute and ${ }^{2}$ Departments of Neuroscience and ${ }^{3}$ Biomedical Engineering, Lerner Research Institute, \\ Cleveland Clinic, Cleveland, Ohio 44195, and ${ }^{4}$ Department of Neurology, University of Minnesota, Minneapolis, Minnesota 55455
}

Control over postinjury CNS plasticity is a major frontier of science that, if conquered, would open new avenues for treatment of neurological disorders. Here we investigate the functional, physiological, and structural changes in the cerebral cortex associated with chronic deep brain stimulation of the cerebellar output, a treatment approach that has been shown to improve postischemia motor recovery in a rodent model of cortical infarcts. Long-Evans rats were pretrained on the pasta-matrix retrieval task, followed by induction of focal cortical ischemia and implantation of a macroelectrode in the contralesional lateral cerebellar nucleus. Animals were assigned to one of three treatment groups pseudorandomly to balance severity of poststroke motor deficits: REGULAR stimulation, BURST stimulation, or SHAM. Treatment initiated 2 weeks post surgery and continued for 5 weeks. At the end, animals were randomly selected for perilesional intracortical microstimulation mapping and tissue sampling for Western blot analysis or contributed tissue for 3D electron microscopy.

Evidence of enhanced cortical plasticity with therapeutically effective stimulation is shown, marked by greater perilesional reorganization in stimulation- treated animals versus SHAM. BURST stimulation was significantly effective for promoting distal forepaw cortical representation. Stimulation-treated animals showed a twofold increase in synaptic density compared with SHAM. In addition, treated animals demonstrated increased expression of synaptic markers of long-term potentiation and plasticity, including synaptophysin, NMDAR1, CaMKII, and PSD95. These findings provide a critical foundation of how deep cerebellar stimulation may guide plastic reparative reorganization after nonprogressive brain injury and indicate strong translational potential.

Key words: cerebello-thalamo-cortical; deep brain stimulation; focal lesion; plasticity; reorganization

\section{Introduction}

Gaining control over CNS plasticity in the recovery process from diffuse or focal brain injuries could represent a significant step toward designing novel neurorestorative treatments. Chronic, electrical stimulation of the brain is now standard of care for managing certain movement disorders (Sjöberg and Blomstedt, 2011), with proven clinical efficacy for suppressing symptoms such as tremor or dyskinesia. However, implementing deep brain

\footnotetext{
Received March 4, 2014; revised May 2, 2014; accepted May 24, 2014

Author contributions: K.B.B., J.T.G., and A.G.M. designed research; J.C., H.F., H.-J.P., and A.G.M. performed research; J.C., H.F., E.P., H.-J.P., Z.C., G.K., J.T.G., and A.G.M. analyzed data; J.C., E.P., G.K., K.B.B., and A.G.M. wrote the paper.

The work was funded by National Institutes of Health Grant R01 HD061363. We acknowledge Kurt Niebaur for his technical assistance with $3 \mathrm{D}$ electron microscopy.

A.G.M. and K.B.B. have a potential financial conflict of interest with this research related to intellectual property and distribution rights from intellectual property in IntElect Medical and possible future distribution in Enspire, ATI, and Cardionomics. The Cleveland Clinic $\mathrm{COI}$ committee has approved a plan for managing the conflict of interest in the conduct of this research. We have adhered to the management plan in the conduct and reporting of research findings.

*J.C. and H.F. contributed equally to this work.

Correspondence should be addressed to Dr. Andre Machado, 9500 Euclid Avenue, Desk S31, Cleveland, $0 \mathrm{H} 44195$. E-mail:machada@ccf.org.

DOI:10.1523/JNEUROSCI.0953-14.2014

Copyright $\odot 2014$ the authors $\quad 0270-6474 / 14 / 349040-11 \$ 15.00 / 0$
}

stimulation (DBS) to augment rehabilitation from lost neurological function resulting in paralysis or reduced level of consciousness has proven to be a much harder task (Baker et al., 2010; Machado et al., 2013). To date, improvements in level of consciousness and functional measures have been reported in a single patient in minimally conscious state by means of bilateral medial thalamic DBS (Schiff et al., 2007; Yamamoto et al., 2010). As well, we have shown previously that DBS targeting the cerebello-thalamo-cortical pathway modulates cerebral cortical excitability (Baker et al., 2010) and improves postischemia motor recovery (Machado et al., 2009). A key question, with significant implications for conditions such as poststroke hemiparesis, traumatic brain injury, and postdeafferentation chronic pain (Dancause et al., 2005; Voss and Schiff, 2009; Gustin et al., 2012) is whether DBS can promote perilesional cortical functional organization, synaptic efficiency, or microstructural reparative plasticity. Here we evaluated functional, physiological, and microstructural mechanisms that may underlie the rehabilitative effects of chronic cerebellar DBS after cortical ischemia (Machado et al., 2013).

\section{Materials and Methods}

Animals

Male Long-Evans rats, weighing 200-224 g at study onset, were individually housed in custom-made caging on a 12:12 h light/dark cycle and 
A

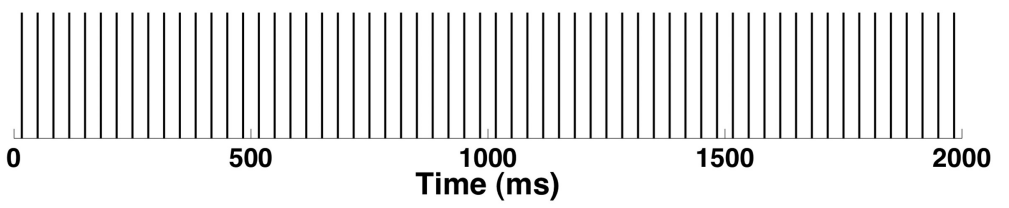

B

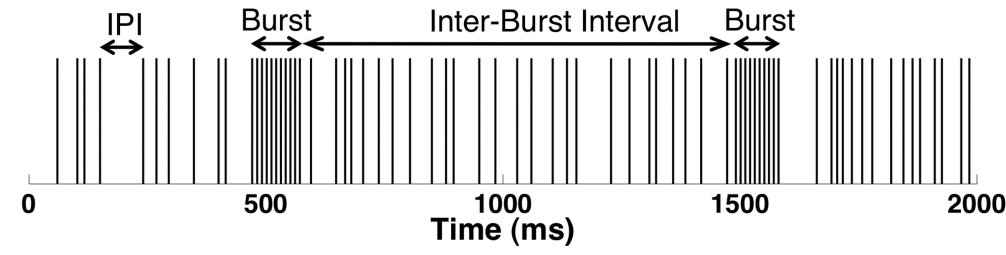

C

Inter-Pulse Interval (IPI)
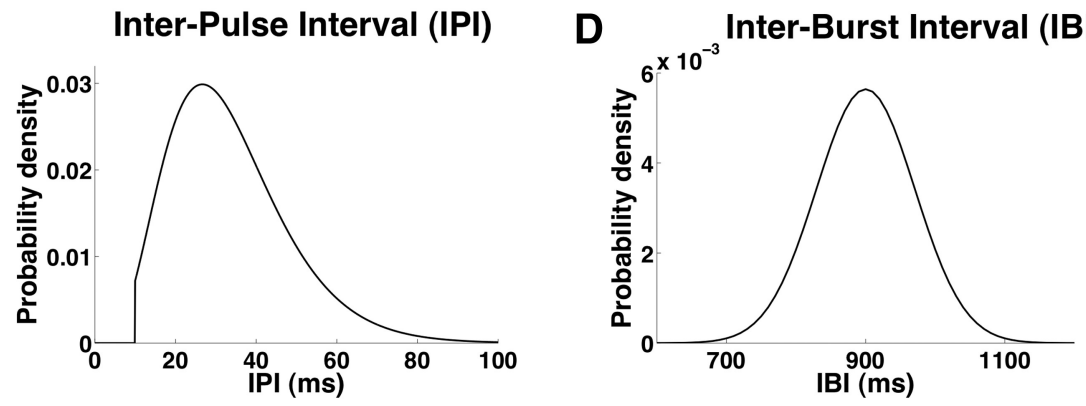

Figure 1. LCN stimulus pulses. $\boldsymbol{A}$, Regular $30 \mathrm{~Hz}$ stimulus pulses ( $\boldsymbol{B}$ ) BURST stimulation pattern. The burst pulses with intraburst pulse interval of 10 and 100 ms duration (10 pulses per burst) were superimposed on the baseline pulses. The IPI of the baseline pulses was modeled with a gamma distribution with the average of 30 pulses per second (pps). C, IPI probability density of the baseline pulses was modeled with a gamma distribution with $\alpha=5$ and $\beta=1 / 5$. The minimum IPI was set 10 ms and the probability density function was scaled to ensure an average of $30 \mathrm{pps}$. $\boldsymbol{D}$, The IBI was modeled with a Gaussian distribution with $900 \pm 71 \mathrm{~ms}$ (mean \pm SD).

mildly food restricted ( $12 \mathrm{~g}$ of food/d ad libitum). Caging was designed to allow behavioral testing and chronic stimulation delivery without manipulation or disconnection of the animal. All behavioral testing was done during the dark phase under controlled red lighting. Animal use and surgical procedures performed were approved by the Institutional Animal Care and Use Committee of the Cleveland Clinic.

\section{Experimental design}

Animals were pretrained on the pasta-matrix task 10 min daily, $5 \mathrm{~d}$ per week for 2 weeks as previously described (Machado et al., 2013). The number and spatial orientation of pasta pieces retrieved were recorded. Pasta was initially presented to the animal on both sides of the matrix, after which pasta was only presented on the side of the matrix that corresponded to the animal's preferred (dominant) paw. The last $3 \mathrm{~d}$ of the second week of training comprised the baseline, prestroke pasta-matrix performance data. Animals that were outside of 2 SDs from the mean performance on the pasta-matrix task during the second week were excluded from further continuation in the study. This was done to prevent animals that could not learn the pasta-matrix task, possibly due to preexisting deficits, from advancing to the main part of the experimentation. Those animals qualifying for continuation underwent stroke induction and electrode implantation, in the same anesthesia, and were then allowed a 1 week recovery. Pasta-matrix training then resumed for $5 \mathrm{~d}$ for 1 week. Animals were then assigned to one of three treatment groups pseudorandomly to severity-match all groups based on mean retrievals observed post stroke. On the last day of the poststroke training week animals were connected to an electrical stimulation commutator system within their home cage. The motor threshold for cerebellar stimulation was determined as previously reported (Baker et al., 2010). Briefly, animals are placed in a transparent cylinder to facilitate visualization from all sides, including underneath. The electrodes are connected to the commutator cable in such a fashion that the rat is as freely roaming in the cylinder as in the treatment cage. Stimulation frequency is increased in stepwise fashion until a reproducible motor response (typically in the ipsilateral forepaw, vibrissae, or torso) is noted. Treatment groups con- sisted of (1) No stimulation, in which stimulators were set to 0 amplitude (SHAM); (2) $30 \mathrm{~Hz}$ continuous isochronous bipolar stimulation at $80 \%$ of threshold (REGULAR); and (3) Intermittent high-frequency trains superimposed on $30 \mathrm{~Hz}$ nonisochronous stimulation (BURST), also at $80 \%$ of threshold. The latter was designed to mimic a Hebbian facilitation paradigm (Hebb, 1949; Bailey et al., 2000) and consisted of a baseline of $30 \mathrm{~Hz}$ stimulation with an interpulse interval (IPI) randomized to a gamma distribution. Gamma distribution was used because the neuronal interspike interval (ISI) can be properly modeled (Miura et al., 2007; Tsubo et al., 2012). The exact parameters of ISI probability distribution model of the lateral cerebellar nucleus (LCN) neurons are not known. We used an approximation with $\alpha=5$ and $\beta=1 / 5$, and scaled the IPI in time with a minimum IPI of $10 \mathrm{~ms}$. The BURST stimulation paradigm had a baseline with a total of 30 pulses in each second. The IPI probability distribution is shown in Figure 1. The bursts were superimposed on the baseline, with a duration of $100 \mathrm{~ms}$ and intraburst IPI of $10 \mathrm{~ms}$. The interburst interval (IBI) had Gaussian random distribution with $900 \pm 71 \mathrm{~ms}($ mean $\pm \mathrm{SD})$ as shown in Figure 1.

Chronic stimulation for the DBS groups was delivered for $12 \mathrm{~h} / \mathrm{d}$, for 5 weeks following group assignment, during the dark phase of the day/night cycle. Pasta-matrix testing was continued during these 5 weeks, $5 \mathrm{~d}$ /week, for 10 min each day, without disconnection from the commutator system. At the conclusion of the 5 weeks of stimulation, an electrolytic lesion was created at the tip of the electrode by DC stimulation $(+30 \mu \mathrm{A}, 30 \mathrm{~s})$.

\section{Ischemia and electrode implantation}

Placement of deep cerebellar electrodes and focal ischemia were conducted as detailed previously (Baker et al., 2010; Machado et al., 2013). Briefly, animals were anesthetized with ketamine $(50 \mathrm{mg} / \mathrm{kg})$ and medetomidine $(0.5 \mathrm{mg} / \mathrm{kg})$ and fixed in a stereotaxic frame (David Kopf Instruments). Skin was retracted and burr holes drilled in the calvaria at three sites corresponding to the motor cortex contralateral to the dominant paw. The coordinates in relation to bregma were as follows: (1) $\mathrm{AP}=-1.0 \mathrm{~mm}, \mathrm{ML}= \pm 2.5 \mathrm{~mm}, \mathrm{DV}=-2.3 \mathrm{~mm}$; (2) $\mathrm{AP}=+1.0 \mathrm{~mm}$, $\mathrm{ML}= \pm 2.5 \mathrm{~mm}, \mathrm{DV}=-2.3 \mathrm{~mm}$; and $(3) \mathrm{AP}=+3.0 \mathrm{~mm}, \mathrm{ML}= \pm 2.5$ $\mathrm{mm}, \mathrm{DV}=-2.3 \mathrm{~mm}$. Ischemia was then induced by intracortical injection of 800 pmol endothelin-1 (EMD Millipore) diluted to $2 \mu \mathrm{l}$ at each coordinate. A $28 \mathrm{G}$ needle was inserted into the brain and injection initiated after a $1 \mathrm{~min}$ pause at a rate of $0.5 \mu \mathrm{l} / \mathrm{min}$. A $1 \mathrm{~min}$ pause was allowed after injection of the first $1 \mu \mathrm{l}$ and a 3 min pause after infusion, before withdrawal of the needle (Windle et al., 2006). Under the same anesthesia, a bipolar macro-electrode (Model MS306; Plastics One) was implanted in the LCN contralateral to the endothelin-1 injections. Briefly, a burr hole was drilled at $\mathrm{AP}=-11.0 \mathrm{~mm}$ and $\mathrm{ML}= \pm 3.6 \mathrm{~mm}$ and the electrode descended to DV $=-6.3 \mathrm{~mm}$. The electrode was secured with dental acrylic and screws. The burr holes from endothelin-1 injection were covered with cellulose paper (Data Sciences International) and tissue adhesive (Vetbond; $3 \mathrm{M}$ ) to form a protective seal. Medetomidine anesthesia was reversed with atipamezole $(1 \mathrm{mg} / \mathrm{kg})$, followed by buprenorphine $(0.05 \mathrm{mg} / \mathrm{kg})$ administration. The animals were allowed to recover with food and water ad libitum for $5 \mathrm{~d}$.

\section{Measures of poststroke plasticity, synaptogenesis, and long-term potentiation}

At the end of the chronic stimulation and training period, animals underwent intracortical microstimulation (ICMS) motor mapping and tis- 


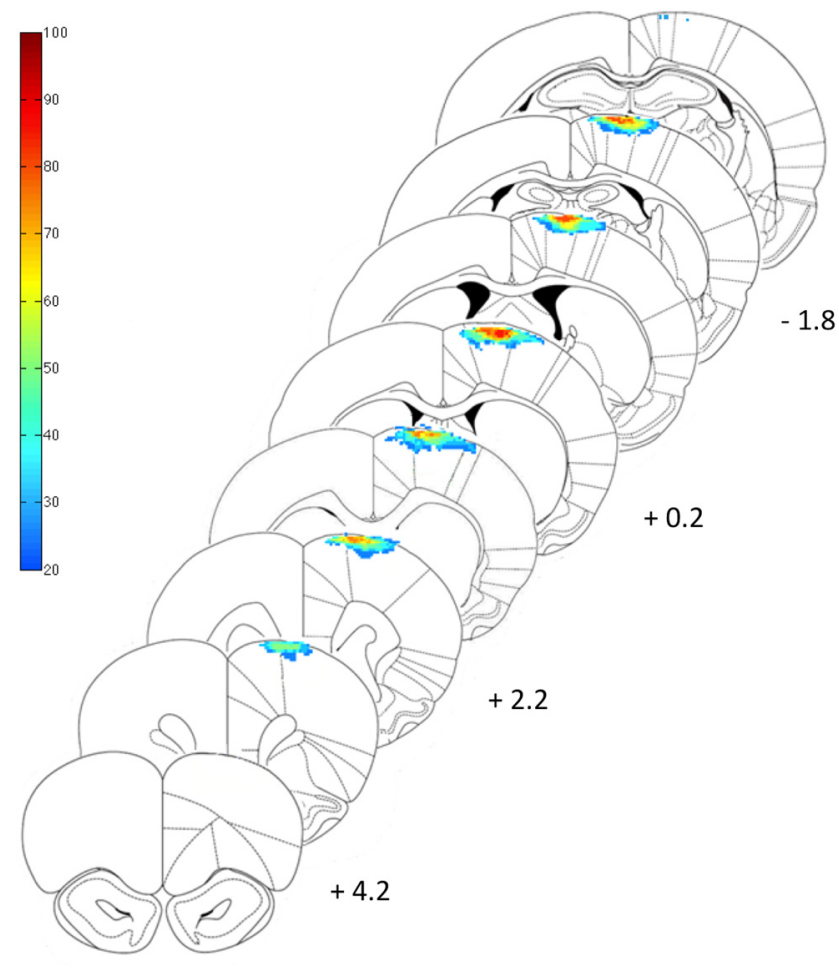

Figure 2. Histological examination of infarct location and volume. Infarct location and volume are overlaid on coronal sections from the Paxinos and Watson Atlas (Paxinos and Watson, 1998). Infarcts spanned from $3.2 \mathrm{~mm}$ anterior to $-2.8 \mathrm{~mm}$ posterior to bregma. Color coding represents the percentage of animals with infarcted tissue present at that pixel. The mean ( \pm SEM) stroke volume was $7.49 \pm 0.72 \mathrm{~mm}^{3}$, while those in the REGULAR, BURST, and SHAM groups were $6.42 \pm 0.69,8.41 \pm 1.34$, and $7.42 \pm 1.75 \mathrm{~mm}^{3}$, respectively, and did not differ between groups $\left(F_{(2,29)}=0.73 ; p=0.49\right)$.

sue was obtained for 3D electron microscopy (3D-EM) and Western blot analysis. Because of the incompatibility for histological preparations between some of these postbehavioral techniques, not all animals were used for every technique. Animals from each group were randomly selected for ICMS mapping and were killed for tissue collection with techniques appropriate for Western blot analysis. The remaining animals were killed with tissue-processing techniques to optimize 3D-EM. Due to the extensive number of penetrations involved in ICMS and concern that these would affect the highly detailed anatomical analysis with 3D-EM, animals undergoing ICMS did not contribute tissue to 3D-EM. The detailed techniques for ICMS, Western blot, 3D-EM, and histology are described below.

\section{ICMS perilesional mapping}

Fifteen animals were administered a bolus of ketamine $(200 \mathrm{mg} / \mathrm{kg})$ and maintained intravenously on ketamine $(75 \mathrm{mg} / \mathrm{kg} / \mathrm{h})$ for the duration of mapping. An approximately $4 \times 8 \mathrm{~mm}$ craniotomy was created over and around the area injected with endothelin, overlying the motor cortex contralateral to the trained forepaw. Once the dura was retracted, a tungsten microelectrode was advanced $1520 \mu \mathrm{m}$ from pial touch for microstimulation. Subsequent penetrations were performed following a grid pattern, with points separated by $1 \mathrm{~mm}$ in each of the ML and AP directions, over the entirety of the exposed brain. Stimulation delivered at each penetration consisted of brief bursts of six charge-balanced squarewave pulses (400 $\mu$ s pulse-width per phase) with an intraburst frequency of $330 \mathrm{~Hz}$. Stimulation was increased until movement was observed, up to a maximum of $1.5 \mathrm{~mA}$. During testing, both limbs were partially supported so that the distal forelimbs and hindlimbs were flexed at $\sim 45$ degrees. Once a movement was evoked, the current was reduced until the movement stopped. The lowest current at each penetration that evoked a discernable motor twitch was recorded as the movement threshold. The movement response at each grid site was classified according to nomen-

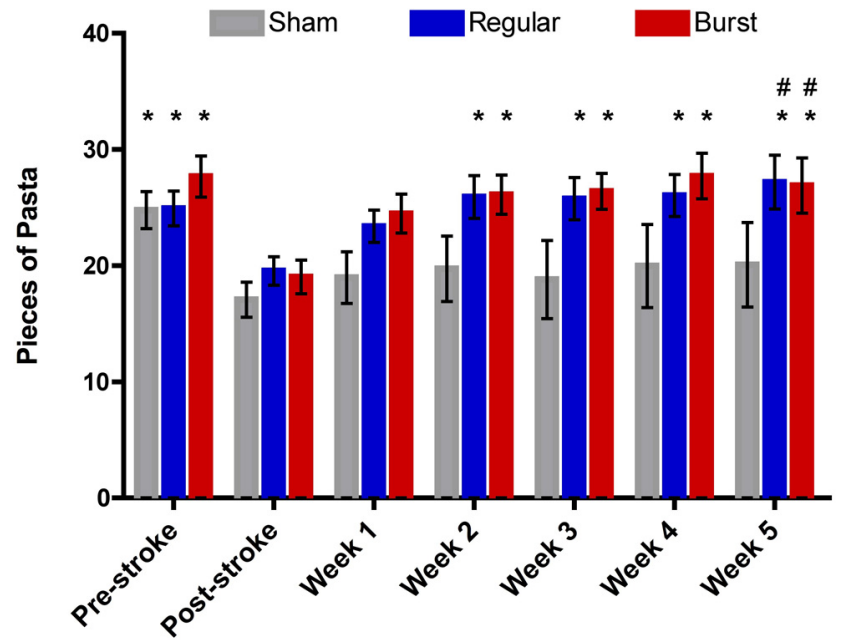

Figure 3. Performance on the pasta-matrix task, indexed as the number of pasta pieces retrieved (mean $\pm S E M)$, over the course of experimentation. There was no evidence of motor recovery in the SHAM group over the experimental phase ( $p>0.99)$. REGULAR- and BURSTtreatment groups showed significant improvement over their poststroke (prestimulation) baseline performances through weeks $2-5$ of stimulation $(p<0.05)$. Neither BURST nor REGULAR showed a difference in performance comparing week 2 to weeks $3-5$, indicating that performance may have approached a plateau by week 2 of stimulation $(p>0.05$ for each comparison). Comparisons were then made between-group at the last week of stimulation. The stimulated groups, REGULAR AND BURST, were not significantly different from each other in motor performance ( $p>0.99$ ); however, both were improved relative to the SHAM treatment group $(27.2 \pm 2.3$ and $26.9 \pm 2.4$ vs $20.3 \pm 3.1$ pieces of pasta retrieved, respectively, $p<$ $0.05)$. ${ }^{*} p<0.05$, significantly different from poststroke baseline, Friedman ANOVA with Dunn's multiple comparisons. \#p $<0.05$, significantly different from SHAM group, KruskalWallis test with Dunn's multiple comparisons.

clature established in previous ICMS studies in rats (Kleim et al., 2003). Movements were classified as belonging to proximal (shoulder/upper arm) or distal (wrist/digits) forelimb, head/neck (including face, jaw, and vibrissa), or hindlimb. When stimulation evoked movement of more than one region, such as the proximal and distal forelimb, the penetration site was included in analysis as part of both regions. A site was considered nonresponsive if no motor response was detected up to 1.5 $\mathrm{mA}$. The entire forelimb region was mapped, including the rostral and caudal areas (rostral forelimb area and caudal forelimb area). In addition to experimental rats, the motor cortices of six naive animals were mapped for comparison, following the same procedure.

We computed several variables used previously to describe changes in cortical motor representation following various interventions. First, we computed the motor representation area $\left(\mathrm{mm}^{2}\right)$, which is one of the most common metrics for understanding motor cortical plasticity following stroke (Gharbawie et al., 2005), training (Kleim et al., 1998), or brain stimulation (Kleim et al., 2003). For each category of movement representation (distal forelimb, proximal forelimb, head/neck, and ipsilateral forelimb), area was calculated by multiplying the number of responsive ICMS sites to that movement category by the corresponding grid area $\left(1 \mathrm{~mm}^{2}\right.$; Tennant et al., 2011). Area of movement representations for a given category was expressed as percentage of the entire area comprising responsive sites within the motor area. Area was normalized in an effort to mitigate the confound of variability in size of the motor cortex across animals as well as to allow for the comparison of one movement representation relative to another. Thresholds representing a category were pooled across animals in each group. For instance, a threshold at each site belonging to the category of proximal forelimb was pooled with thresholds of the same category in other animals in that group.

\section{Western blot analysis}

Our group previously showed that motor rehabilitation associated with chronic stimulation of the dentatothalamocortical pathway is paralleled by greater expression of synaptophysin in immunohistochemistry 

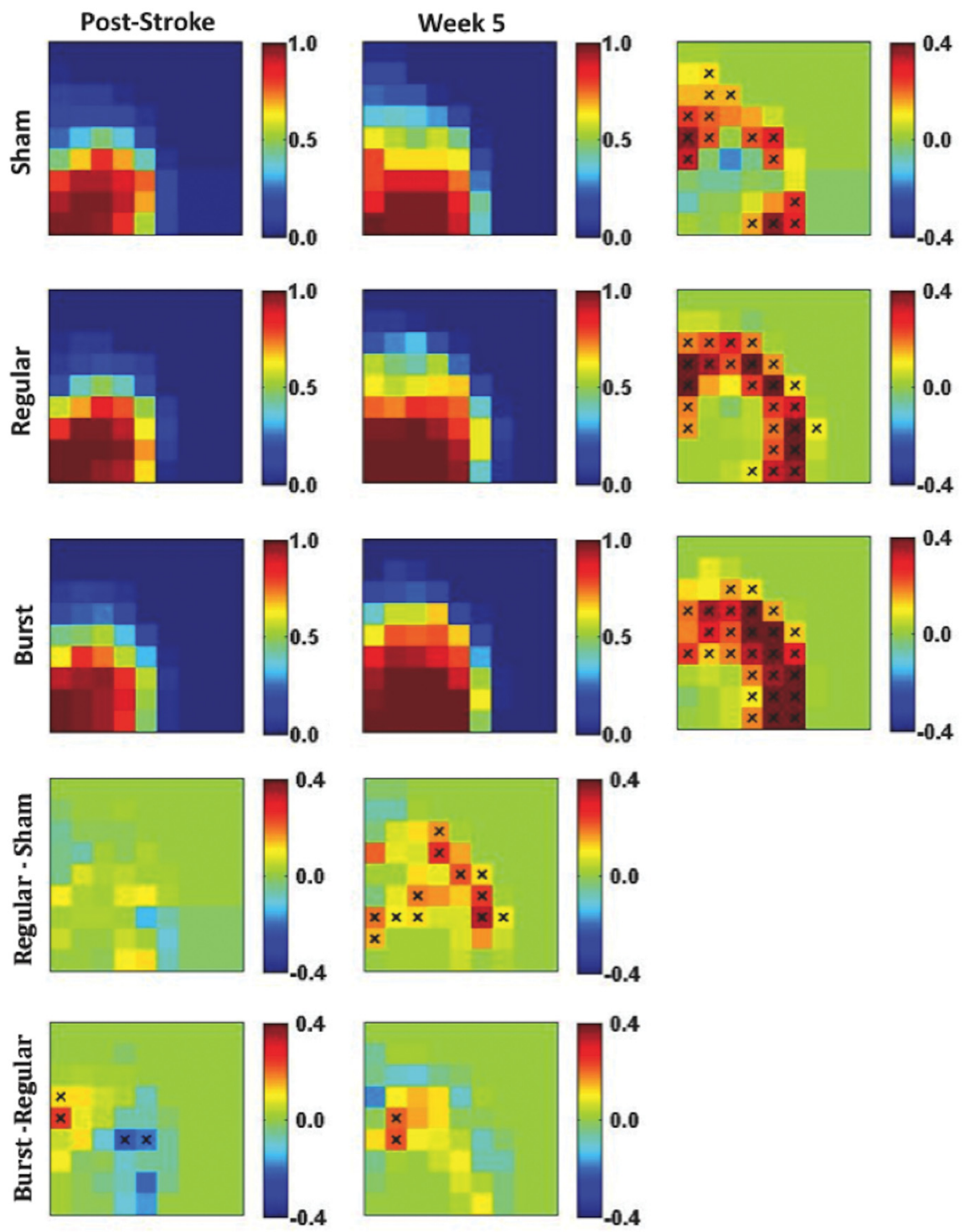

Figure 4. Graphic representation of the frequency of retrieval from each slot of the pasta matrix. Each of the 13 plots represents a view from above of one-half of the pasta matrix corresponding to the dominant paw of each animal. Matrices were plotted on superimposed templates, with the left side inverted on the right-sided template to account for differences in paw dominance across animals. The bottom left corner of each plot corresponds to the location of the vertical slot through which the rat's paw can reach onto the opposite side of the pasta matrix. Hence, pasta pieces represented toward the right and top of each plot are lateral and rostral on the matrix, respectively. Each " $X$ " denotes a between-group (bottom row) or within-group (right column) difference $(p<0.01)$ in frequency of pasta retrieval at that location, for the indicated comparison. While all groups exhibited improved performance on the pasta matrix task from the poststroke week to week 5 of stimulation (rows 1-3, column 3), the stimulated groups showed more extensive gains. All groups show some improved performance in both the rostral and lateral regions of the matrix. Comparisons between groups at week 5 of stimulation reveal that the motor behavioral improvements observed in the REGULAR group compared with SHAM comprise mostly gains in the rostrolateral region of the matrix (row 4, column 2). When comparing REGULAR and BURST groups, we see significant differences in pasta-matrix spatial performance favoring the BURST group that are restricted to the medial region of the matrix (row 5, column 2).

(Machado et al., 2013). In this experiment, the effects of stimulation on a family of proteins that play a key role in long-term potentiation (LTP) and synaptic plasticity were evaluated, namely synaptophysin, CaMKII, PSD95, and NMDAR1. After undergoing intracortical mapping, rats were killed rapidly and the brains quickly removed for dissection in an ice-cooled dish. Naive rats, used for comparison of ICMS results, also contributed tissue to Western blot analysis. Tissue samples were obtained from the perilesional areas as well as from corresponding areas in the contralesional hemisphere. For additional control, samples were also obtained from the ipsilesional visual cortex. The remainder of the intact brain was immersion perfused in $4 \%$ PFA for histological processing.
Western blot samples were stored at $-80^{\circ} \mathrm{C}$ until processed. Samples were homogenized in a lysis buffer [ $50 \mathrm{~mm}$ Tris, $1 \mathrm{~mm}$ EDTA, $0.35 \%$ NA deoxycholate, $150 \mathrm{~mm} \mathrm{NaCl}, 1 \%$ Igepal, $\mathrm{H}_{2} \mathrm{O}$, and $10 \mu \mathrm{l}$ of protease inhibitor mixture (Sigma) per $100 \mathrm{mg}$ of tissue], incubated on ice for $30 \mathrm{~min}$ and then centrifuged $(13,000 \times \mathrm{g}$, $15 \mathrm{~min})$. Protein levels of the collected supernatants were measured using the Bradford assay (Bio-Rad). Proteins were separated in a SDS-PAGE gel and blotted onto a nitrocellulose membrane. Membranes were incubated at $4^{\circ} \mathrm{C}$ overnight with the following primary antibodies: anti-CaM Kinase II $\alpha$-subunit [1:5000 in $1 \%$ BSA in TBS $/ 0.1 \%$ Tween (TBST); Millipore; RRID:AB_309787], anti-PSD95 (1:1000 in $1 \%$ BSA in TBST; Abcam; RRID: AB_444362), anti-NMDAR1 (1:1000 in $1 \%$ BSA in TBST; Abcam; RRID:AB_776808), and anti-synaptophysin (1:2000 in 1\% BSA in TBST; Millipore; RRID:AB_1977519). Equal loading was confirmed using anti-GAPDH (1: 5000 in 1\% BSA in TBST; Millipore; RRID: AB_10615768), which is routinely used for normalization. Membranes were washed with TBST and incubated with horseradish peroxidase-conjugated secondary antibody ( $1: 5000$ in $1 \%$ BSA in TBST; Sigma; RRID: AB_2314650). Secondary antibodies were visualized using enhanced chemiluminescence kits (Pierce) followed by an exposure to $\mathrm{x}$-ray film for detection. Immunoblot bands were quantified using NIH ImageJ1.32. Results were calculated and graphically shown as the ratio of CaMKII, NMDAR1, PSD95, or synaptophysin to GAPDH.

\section{D-EM}

3D-EM was performed on a Carl Zeiss Sigma VP scanning EM fitted with a 3View inchamber ultramicrotome system and Gatan high sensitivity, low-kV BSE detector. Tissue preparation and imaging were performed as previously described (Knott et al., 2008; KiryuSeo et al., 2010). Briefly, rats were perfused with cacodylate-buffered $2.5 \%$ glutaraldehyde and $4 \%$ paraformaldehyde. Brains were removed and postfixed in the perfusion buffer for $24 \mathrm{~h}$. Vibratome sections containing the areas of interest were then treated with $\mathrm{OsO}_{4}$ ferricyanide, followed sequentially by thiocarbohydrazine, aqueous $\mathrm{OsO}_{4}$, aqueous uranyl acetate, and Walton's lead aspartate stain, then embedded in Epon resin. The vibratome sections were examined under the light microscope and trimmed to the location of interest. For each block, three $20 \times 20 \mu \mathrm{m}$ areas at $\sim 100,200$, and $300 \mu \mathrm{m}$ from the lesion border were photographed. The ultrastructural $3 \mathrm{D}$ study of the samples was performed using a Helios 650 dual beam FIB (FEI) system equipped with G2 or G3 SliceView operating software. Serial images of the block surface were generated by automated repeated cycles of cutting and scanning. Images were acquired using a $2 \mathrm{kV}(21-84 \mathrm{pA})$ beam in high-resolution mode using the through lens detector in backscattered electron mode. Sets of 250-500 images at $80 \mathrm{~nm}$ steps (i.e., section thickness) were obtained at $17 \mathrm{~nm} /$ pixel resolution. Images were registered, corrected for histogram, and derivative stacks were generated using Fiji software. Distances and distributions were measured directly or calculated using 3D distance formula. Montage images were constructed from multiple single slices 
A
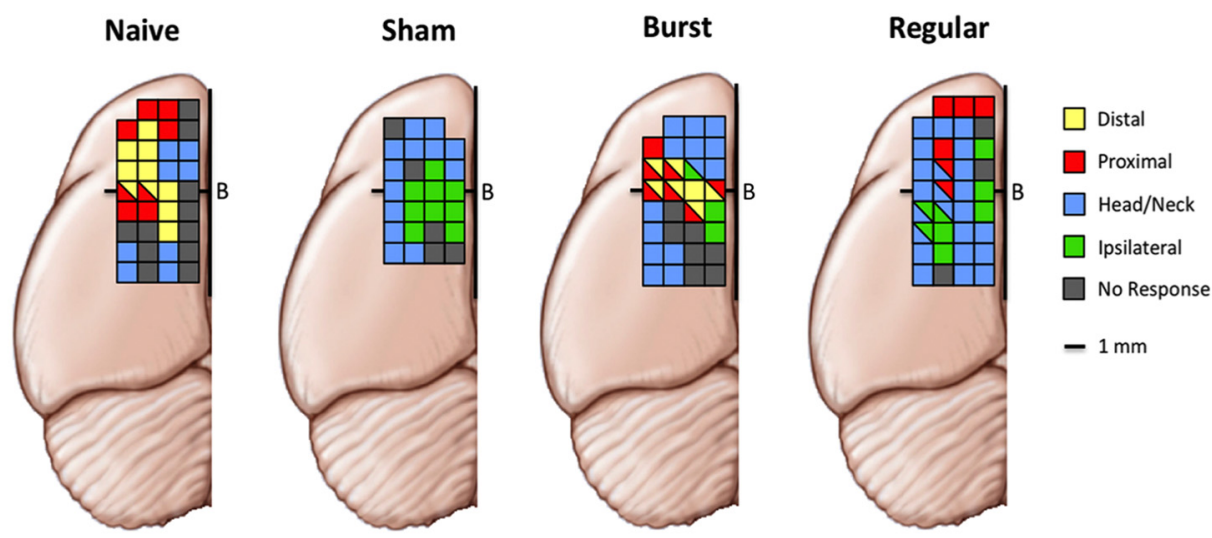

B
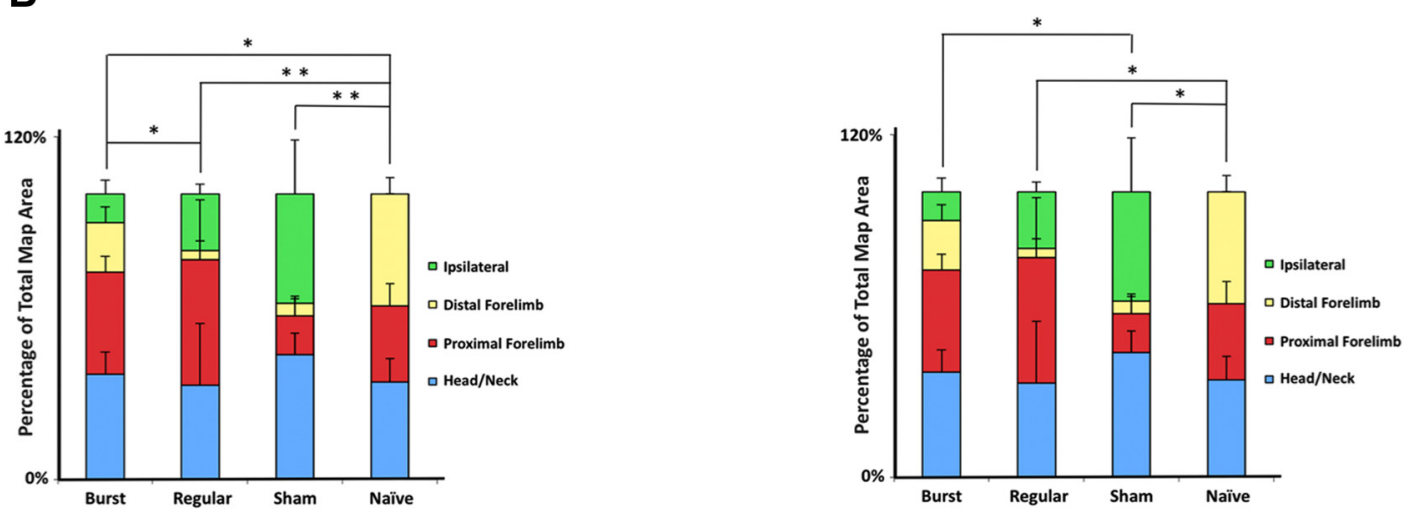

Sham

C

Naive

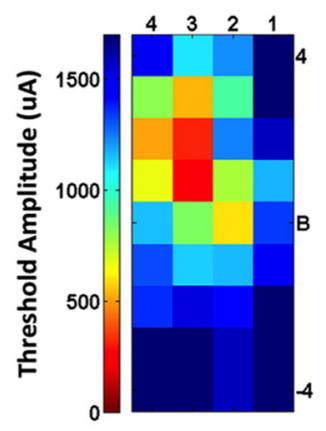

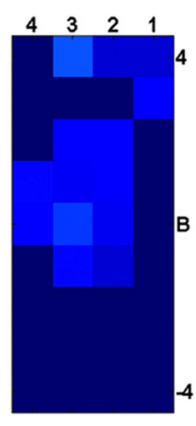

Burst

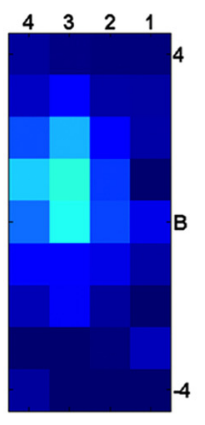

Regular

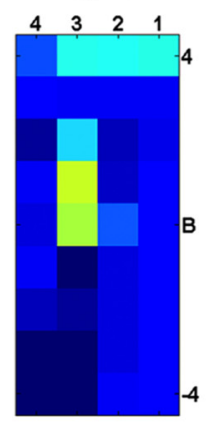

D

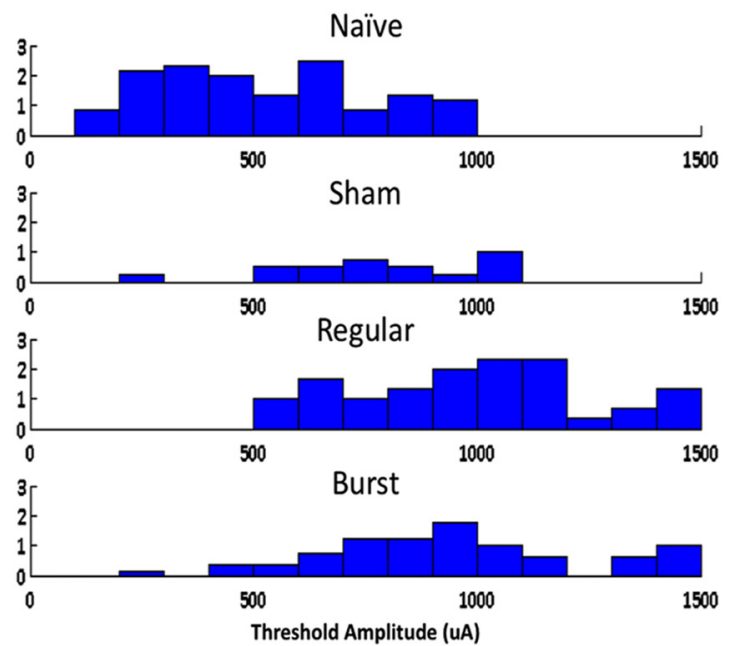

Figure 5. ICMS mapping following treatment. $A$, Maps shown are from representative animals of each group ( $B$, bregma). Squares divided into two colors depict locations where movements consistent with two different categories were elicited simultaneously. $\boldsymbol{B}$, Bar graph representing the percentage of movement category elicited by ICMS, per group. Left, Shows the statistically significant differences for representation of distal forelimb categories across groups. The graph on the right (same data) shows the significant differences (Figure legend continues.) 
through the same image stack. To quantify the number of synapses per unit volume, three image stacks of $5 \times 5 \times 5 \mu \mathrm{m}$ volume were generated from each area and synapses were counted from each stack by investigators blinded to the treatment condition. For quantitative analysis, we report the average synapse count from the three stacks.

\section{Stroke volume quantification and electrode} location verification

Following completion of behavioral analysis, animals were killed as previously described for each postbehavioral measure. Briefly, brains from animals that contributed to the Western blot analysis were immersion perfused in $4 \%$ PFA while those that contributed to the 3D-EM analysis were perfused with a glutaraldehyde/PFA solution. Brains were subsequently sliced at $40 \mu \mathrm{m}$ thickness and every other section of the cerebrum Nissl stained to visualize and calculate stroke volume. Every other cerebellar slice was mounted and PerlsDAB stained for evaluation of electrode location. Stroke volume was then quantified and plotted with the corresponding location over the atlas (Paxinos and Watson, 1998), as previously described (Park et al., 2013). Electrode location relative to the lateral cerebellar nucleus was verified for each animal.

\section{Data analysis}

Behavioral. The total number of pasta pieces retrieved per week in the motor task was compared within each group by a Friedman ANOVA with Dunn's multiple comparisons. Between-group comparisons were made by a Kruskal-Wallis test with Dunn's multiple comparisons. The spatial orientation of pasta retrieval was analyzed as previously described (Machado et al., 2013). Briefly, matrices were plotted on superimposed templates, with matrices inverted as needed to account for differences in paw dominance across animals. The probability of pasta retrieval at each location was calculated as a proportion of retrieved pasta over the number of total trials and compared using its approximation to a normal distribution. This approximation was performed for each point in the pasta matrix and was accepted as different if the analyzed point and at least one neighboring point was significantly different between conditions $(p<0.05$; joint probability $p<0.01)$.

Post behavioral. Area of ICMS mapping data were analyzed using a one-way ANOVA with LSD used to conduct post hoc between-group comparisons with correction for multiple comparisons. Western blot, 3D-EM, and threshold values obtained from mapping, and stroke volumes were analyzed with a one-way ANOVA with Student-NewmanKeuls post hoc tests; $p<0.05$ was considered significant. All data are presented as the mean \pm SEM. More detail is provided in each section.

\section{Results}

\section{Chronic deep cerebellar stimulation promotes} motor recovery

Forty-one animals survived electrode implantation and ischemia. Seven were excluded due to lack of motor deficit post stroke. Five additional animals were excluded from the study due to electrode dislodgement before completion of 5 weeks of stimulation. Thus, 29 animals completed the study (SHAM: $n=7$, REGULAR: $n=$

\section{$\leftarrow$}

(Figure legend continued.) for ipsilateral representation; ${ }^{*} p<0.05,{ }^{* *} p<0.001$. C, Color plot showing the mean threshold for eliciting forelimb (proximal or distal) movements at each penetration site. Stimulation was not delivered above 1.5 mA. D, Histogram demonstrating the distribution of threshold amplitudes for distal and proximal representations by group. Thresholds are grouped into $100 \mu$ A bins; SHAM: $n=4$, REGULAR: $n=3$, BURST: $n=8$, NAIVE: $n=6$.
13, BURST: $n=9$ ) with all animals demonstrating infarct localization and volume consistent with our model (Machado et al., 2013; Fig. 2). All cerebellar electrodes were observed to be within the targeted region.

All groups demonstrated a significant poststroke deficit in the pasta-matrix task ( $p<0.05$; Fig. 3 ), with no motor recovery observed in the SHAM group across the 5 week treatment phase. At the fifth week, both REGULAR- and BURST-treated animals demonstrated significant motor recovery, relative to the SHAM $(p<0.05$, Kruskal-Wallis) group as well as to their individual poststroke, prestimulation baseline ( $p<0.05$, Friedman analysis; Fig. 3). Analysis of the spatial pattern of pasta retrieval from the matrix revealed that animals in the REGULAR group had significantly greater motor gains than SHAM in rostrolateral regions of the matrix. Moreover, BURST animals outperformed those animals in the REGULAR group in a spatially restricted fashion, marked by greater retrieval frequency toward the medial region of the matrix (Fig. 4).

\section{Deep cerebellar stimulation promotes restoration of perilesional cortical motor representation}

After completion of behavioral analysis, a subset of animals was selected at random from each of the three groups for ICMS functional mapping of the motor cortex followed by Western blot studies for markers of LTP and synaptic plasticity. An additional, fourth group $(n=6)$ of surgically and treatment-training naive controls (NAIVE) was added for comparison. We computed several variables used to describe changes in cortical motor representation. First, we computed the motor representation area $\left(\mathrm{mm}^{2}\right)$, which is one of the most common metrics for understanding motor cortical plasticity following stroke (Gharbawie et al., 2005), training (Kleim et al., 1998), or brain stimulation (Kleim et al., 2003). For each category of movement representation (distal forelimb, proximal forelimb, head/neck, and ipsilateral forelimb), area was calculated by multiplying the number of responsive ICMS sites to that movement category by the corresponding grid area $\left(1 \mathrm{~mm}^{2}\right.$; Tennant et al., 2011). The percentage of the total motor cortical map that induced distal forelimb movement was found to differ among the four groups $\left(F_{(3,20)}=\right.$ $13.84, p<0.001)$. Post hoc tests revealed that the area of contralateral, distal forelimb representation was highest in NAIVE rats 

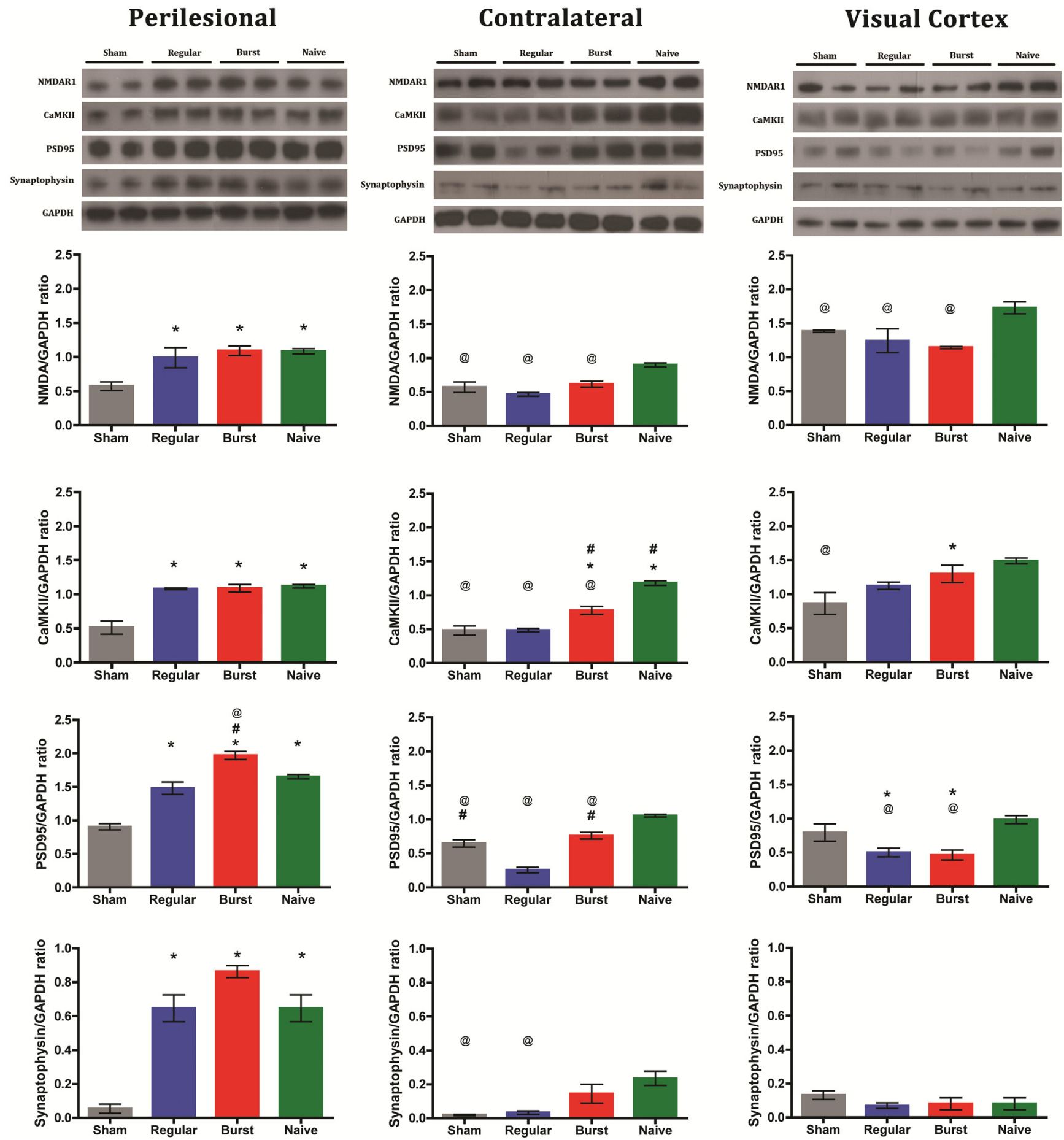

Figure 7. Deep cerebellar stimulation enhances synaptic protein expressions in perilesional areas. Synaptic proteins are normalized against GAPDH control values. One-way ANOVA, StudentNewman-Keuls post hoc test, ${ }^{*} p<0.05$ compared with SHAM, $\# p<0.05$ compared with REGULAR, ${ }^{\circledR} p<0.05$ compared with NAIVE rats, $n=4-8$ per group.

$(37.85 \pm 3.7 \%)$ compared with BURST $(17.91 \pm 3.80 \%, p=$ $0.001)$, SHAM $(6.35 \pm 3.83 \%, p<0.001)$, and REGULAR $(3.03 \pm 3.03 \%, p<0.001)$ groups. Of all animals affected by stroke, the BURST stimulation group showed the greatest percentage area of distal forelimb representation, which was significantly greater than the REGULAR or SHAM groups $(p<0.05$; Fig. 5A, third from left; $B$, left). The percentage area devoted to ipsilateral forelimb representation also varied $\left(F_{(3,20)}=5.24, p=\right.$ $0.01)$ across groups, with responses absent in NAIVE animals but present in all stroke groups. Post hoc comparisons showed that the SHAM and REGULAR stimulation group had larger ipsilateral forelimb representation than NAIVE rats $(30.20 \pm 12.62 \%$, $p<0.01)$ and $23.89 \pm 2.35 \%, p<0.05$, respectively). However, BURST-treated animals elicited the fewest ipsilateral responses of all poststroke groups, with significantly smaller ipsilateral representation than SHAM $(11.14 \pm 3.88 \%$ vs $30.20 \pm 12.62 \%, p=$ 0.026 ; Fig. $5 B$, right). The results indicate that DBS, particularly BURST treatment, promoted greater restoration of perilesional cortical representation of the affected forepaw while minimizing representation of the nonaffected side. 


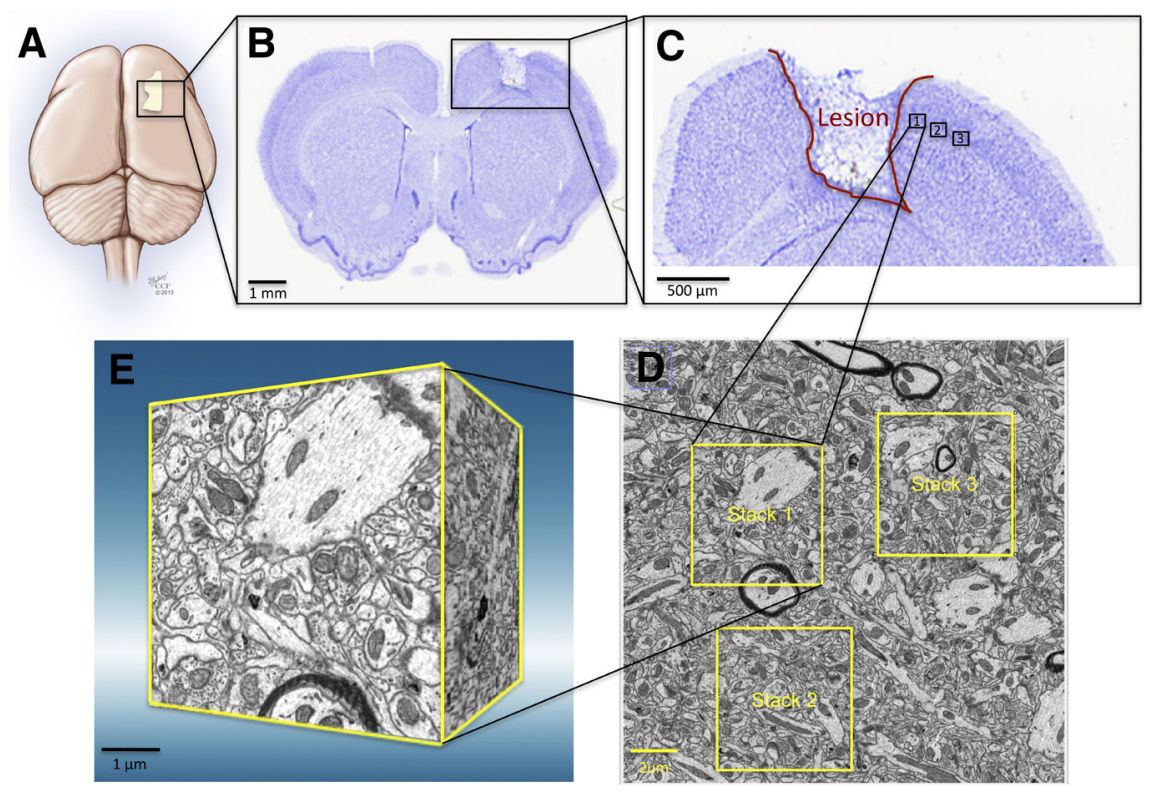

Figure 8. Representative digital images of $3 \mathrm{D}-\mathrm{EM}$ of an ischemic rat. $A-C$, Schematic of rat brain showing location of the perilesional area where tissue samples were obtained for $3 D-E M(C ; A P=$ bregma $+1.0 \mathrm{~mm}) . \boldsymbol{D}$, Example of three image stacks of $5 \mu \mathrm{m}$ edge cubes from one perilesional area. $\boldsymbol{E}, 3 \mathrm{D}$ reconstruction of a $125 \mu \mathrm{m}^{3}$ cube containing 63 slices at $80 \mathrm{~nm}$ per slice.

In addition to motor representation area, we also evaluated motor thresholds for each movement category (Fig. 5C). NAIVE animals exhibited a large area of representation with many regions of high excitability, which were not observed in the SHAM group. There was a significant main effect of treatment when analyzing distal and proximal thresholds $\left(F_{(3,217)}=44.24, p<\right.$ 0.0001). NAIVE animals, as expected, demonstrated the lowest threshold $(539.5 \pm 25.13 \mu \mathrm{A})$, with increasingly higher thresholds observed in the SHAM $(799.7 \pm 62.19 \mu \mathrm{A})$, BURST (971.2 \pm $34.47 \mu \mathrm{A})$, and REGULAR (996.7 $\pm 46.17 \mu \mathrm{A})$ groups. Post hoc comparisons revealed that the threshold differences between the two stimulation groups were significant relative to both the SHAM and NAIVE animals $(p<0.05)$. The results indicate that cortical excitability (at least under anesthesia) was not associated with behavioral gains or reorganization of forelimb motor cortical representation. We further examined the differences in motor threshold as a function of the distal and proximal limb (Fig. 5D), correcting for the difference in animal numbers across groups. An overall shift to higher thresholds was observed across all animals that received a stroke, compared with NAIVE.

\section{Stimulation promotes the expression of markers of long-term potentiation and synaptogenesis}

To better understand the structural changes that may play a role in the observed functional changes, we then evaluated the effect of treatment on the expression of a family of proteins known to play a key role in synaptic plasticity. Tissue sections for Western blot analysis were sampled from the perilesional cortex, the corresponding area on the contralateral hemisphere, and the visual cortex ipsilateral to the lesion (Fig. 6). Results were calculated as the ratio of NMDAR1, CaMKII, PSD95, or synaptophysin to GAPDH. GAPDH levels were consistent across groups. A significant main effect of treatment for $\operatorname{NMDAR} 1\left(F_{(3,15)}=7.46, p<\right.$ $0.01)$, CaMKII $\left(F_{(3,15)}=25.46, p<0.001\right)$, PSD95 $\left(F_{(3,15)}=\right.$ $51.50, p<0.001)$, and synaptophysin $\left(F_{(3,15)}=33.12, p<0.001\right)$ was noted in the perilesional cortex (one-way ANOVAs were performed separately for each protein). Post hoc analysis revealed that NAIVE and both REGULAR and BURST stimulations were associated with significantly higher levels of NMDAR1, CaMKII, PSD95, and synaptophysin compared with SHAM-treated rats in the perilesional cortex (Fig. 7). Of note, levels of PSD95 were found to be significantly higher $(p<0.05)$ in the BURST as compared with both the REGULAR and NAIVE groups in the perilesional cortex. Changes in protein expression were also found in the corresponding area on the contralesional cortex. A significant main effect of treatment for NMDAR1 $\left(F_{(3,15)}\right.$ $=14.82, p<0.001)$, CaMKII $\left(F_{(3,15)}=\right.$ $45.06, p<0.001), \operatorname{PSD} 95\left(F_{(3,15)}=59.15\right.$, $p<0.001)$, and synaptophysin $\left(F_{(3,15)}=\right.$ $8.34, p<0.01)$ was noted. Overall, these results suggest a role for LTP-related mechanisms of synaptic plasticity in this model.

\section{Stimulation promotes synaptogenesis}

As a next step, we evaluated the effects of stimulation on synaptic density. Given that stimulation was only initiated 2 weeks after ischemia, at a time when infarcts are well established, it is unlikely that greater synaptic density compared with SHAM would indicate a protective effect of stimulation. Rather, it points toward promotion of synaptogenesis. Although synaptophysin alone indicated the likelihood of a greater number of synapses in stimulation-treated animals (particularly BURST), its measurement does not allow for a distinction to be made between fully formed, active synapses and inactive ones. Given that synaptophysin was strongly expressed in the perilesional cortex, we examined this area by counting active synapses directly using 3D-EM (Fig. 8) in a subset of animals randomly selected from each treatment group. We found that the REGULAR and BURST stimulation groups had significantly greater perilesional synaptic density compared with SHAM animals at each location within the perilesional area (Fig. 9). The mean number of synapses counted within each $5 \mu \mathrm{m}$ cube for animals in REGULAR, BURST, and SHAM groups were 109.1 $\pm 16.0,120 \pm 22.2$, and $39.6 \pm 10.6$, respectively $\left(F_{(2,6)}=9.90, p<0.05\right)$ at the site 100 $\mu \mathrm{m}$ from the edge of the stroke and $91.8 \pm 18.9,104.5 \pm 21.6$, and $48.1 \pm 14.9$, respectively $\left(F_{(2,6)}=6.46, p<0.05\right)$ at the site $300 \mu \mathrm{m}$ from the lesion edge. One-way ANOVA was performed independently for each cortical region.

\section{Discussion}

DBS of the LCN has been previously shown to promote motor recovery after ischemia (Machado et al., 2009, 2013). The present work aimed at evaluating possible mechanisms associated with these rehabilitative effects and to assess how DBS may promote plasticity after cerebral injury. Chronic stimulation promoted functional reorganization and microstructural changes in postinfarct, perilesional cortex and reproduced the motor rehabilitative effects of our prior work. Motor representation in the perilesional cortex is strongly correlated with recovery of function after stroke (Nudo et al., 1996). In particular, larger areas of cortical representation for the affected limb are associated with improved motor outcomes and mapping of motor representation is one of the most common metrics for measuring the success of poststroke 


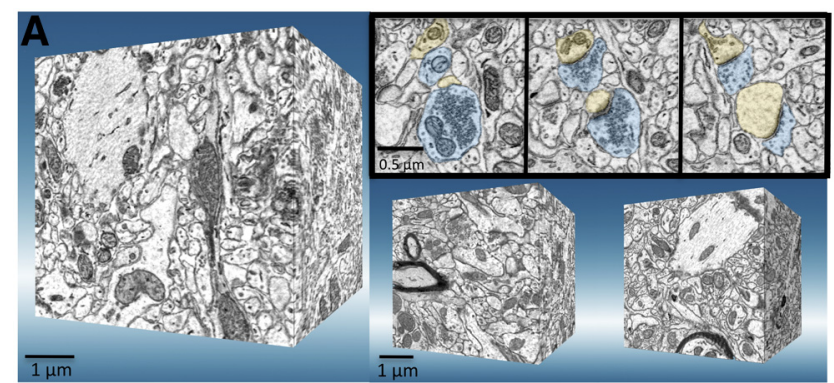

B

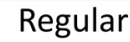

\section{Burst}
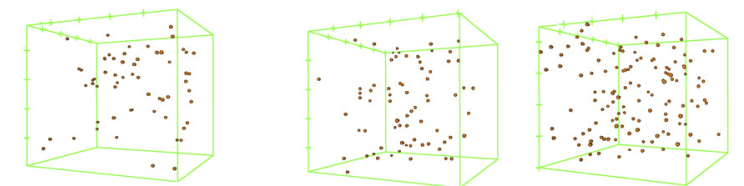

C

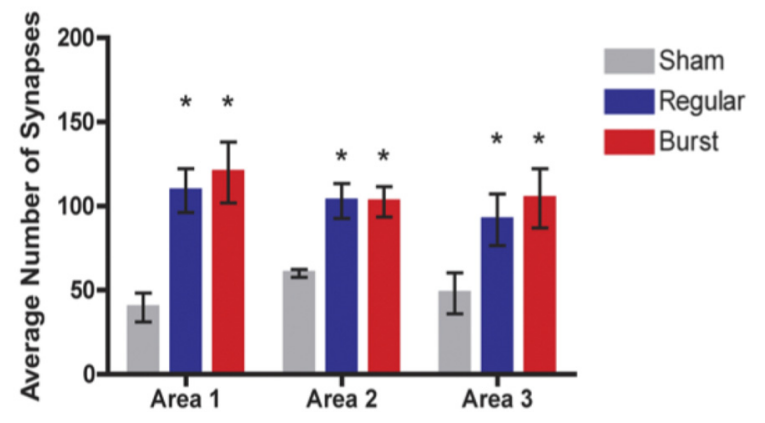

Figure 9. A, Representative $125 \mu \mathrm{m}^{3}$ samples. Left, The large cube is a sample from a SHAM-treated animal. Right top, Representative digital images showing the progression through consecutive slices of the image stack with presynaptic neurons in blue and postsynaptic neurons in yellow. The slice in the middle is centered on the synapse. Active synapses have a clear postsynaptic density. Right bottom, Representative samples from REGULAR- and BURSTtreated animals. $B, 3 D$ cubic rendering of the location of the active synapses in each of the three representative samples from $\boldsymbol{A}$. C, Data summary for the number of synapses per $125 \mu \mathrm{m}^{3}$ volume per treatment group at 100 (Area 1), 200 (Area 2), and $300 \mu \mathrm{m}$ (Area 3) away from the lesion (one-way ANOVA was performed for each area individually, Student-Newman-Keuls post hoc; ${ }^{*} p<0.05$ significantly different from SHAM.

plasticity (Gharbawie et al., 2008). In our study, both patterns of DBS enhanced ipsilesional reorganization beyond that observed with motor training alone (SHAM). SHAM-treated animals presented with a profound loss of representation of the affected forepaw in the perilesional cortex, compared with NAIVE animals. Likewise, SHAM-treated animals had greater perilesional representation for the nonaffected (ipsilateral) paw, which is abnormal. Stimulation was associated with significantly greater motor representation of the affected forepaw, proximal and distal, as well as decreased representation of the nonaffected forepaw. In particular, BURST stimulation had a reparative effect on cortical motor representation that most readily approached normal, characterized by the greatest area of contralateral distal forelimb representation and the least ipsilateral representation. ICMS thresholds required to elicit motor responses for each movement category were also analyzed. There were no significant differences in threshold between the stimulation groups, but both stimulation groups had significantly higher thresholds than SHAM or NAIVE animals. This indicates that, at least in the anesthetized state, increments in cortical excitability (i.e., reductions in threshold) did not parallel functional gains associated with stimulation (Baker et al., 2010).

The enhanced functional reorganization associated with DBS was paralleled by significant physiological changes, including an increase in markers of LTP and synaptogenesis. Although motor training is thought to promote recovery via synaptic plasticity(Dimyan and Cohen, 2011), animals that received motor training only (SHAM) in the present experiment showed no meaningful recovery and exhibited reduced expression of all four measured proteins (i.e., CaMKII, PSD-95, NMDA, and synaptophysin) in the perilesional cortex relative to NAÏVE. Synaptic plasticity has been associated with increased perilesional expression of PSD95 (Pagnussat et al., 2012), a membrane-associated guanylate kinase signaling scaffold protein in glutamatergic synapses. PSD95 activity during LTP is, in turn, regulated by CaMKII phosphorylation of S73 and considered important for both structural (i.e., spine growth) and functional (i.e., LTP) cortical changes (Steiner et al., 2008). Elevation of CaMKII is considered both necessary and sufficient for promotion of LTP (Nicoll and Roche, 2013). Our data showed a concomitant elevation of CaMKII, PSD95, and NMDAR (which activates CaMKII) expression in stimulation-treated animals compared with SHAM, further corroborating a role for LTP in stimulation-related recovery. BURST stimulation was uniquely efficient in promoting restoration of distal forelimb representation and also associated with significantly greater expression of PSD95 than SHAM or REGULAR stimulation.

In addition to promoting Hebbian facilitation (Bailey et al., 2000; Buetefisch et al., 2011), the BURST paradigm was designed to partially reproduce natural bursting activity common to the dentate nucleus. Our rationale is partially based on the detrimental effects of crossed-cerebellar diaschisis to recovery of motor function post stroke (Takasawa et al., 2002). We have proposed that exogenous, chronic electrical stimulation may compensate for the reduction of intrinsic, poststroke dentatothalamocortical activity secondary to crossed-cerebellar diaschisis (Machado and Baker, 2012). In accordance to this working hypothesis, we have shown previously that isochronic, $30 \mathrm{~Hz}$ LCN stimulation facilitated motor recovery in the rodent cortical stroke model (Machado et al., 2013). Further, we have shown that continuous stimulation of the dentatothalamocortical pathway at $30 \mathrm{~Hz}$ significantly increases cortical excitability (Baker et al., 2010). However, the cerebellar nuclei do not function at a constant beta-band frequency in vivo, instead modulating continuously in relation to motor activity and behavior. The bursting paradigm used in the present study was designed as part of an iterative attempt to approximate this intrinsic modulation, anticipating that this could have an additive, positive rehabilitative impact while at the same time recognizing that it would not re-create normal cerebellar function. To this end, the intraburst frequency used in this paradigm was based on prior electrophysiological studies examining dentate nucleus activity (Thach, 1970; Goodkin and Thach, 2003; Aumann and Fetz, 2004). Our data largely corroborates the hypothesis that stimulation paradigms containing bursting activity natural to the dentate nucleus could have greater rehabilitative effects than regular isochronous stimulation. While the total pasta retrieval of animals in the BURST cohort was not different from those in the REGULAR group, BURST-treated animals achieved significantly greater frequency of retrieval from the medial area of the matrix, suggesting greater distal forelimb control in that direction. The increased expression of PSD95 associated with BURST points to the possibility that this pattern of stimulation further enhanced macroscopic cortical reorganization and recovery via promotion of LTP and synaptic plasticity.

Stimulation treatment was associated with significant increments in perilesional synaptophysin expression, indicating synaptogenesis. In addition to measuring protein expression with Western blot, synapses were individually counted with 3D-EM-a 
direct and reliable method for measuring synaptic density. Animals treated with both stimulation paradigms, REGULAR and BURST, presented with greater synaptic density than SHAM. While we cannot rule out the possibility that stimulation had a protective effect against synaptic loss, this is unlikely. Stimulation was initiated 2 weeks after ischemia, at a time when the infarct is already well established. The data suggest that stimulationrelated motor recovery may be mediated, at least in part, by synaptogenesis. Our findings indicate that chronic DBS of the dentatothalamocortical pathway can significantly enhance cortical perilesional plastic reorganization and motor recovery.

The translational value of the present findings can be significant for human postinjury rehabilitation. DBS is a standard technology, routinely implemented in the care of common neurological disorders such as Parkinson's disease (Machado et al., $2012 \mathrm{~b}$ ). Because the techniques are well established (Machado et al., 2012a), physicians often use this technology in less common disorders (Ghosh et al., 2012; Lim et al., 2013) and in a number of clinical trials (Mayberg et al., 2005; Laxton and Lozano, 2013; Plow et al., 2013). Hence, translation of novel DBS therapies can be accomplished with existing tools, either in their current or modified versions. Our approach to human use would not represent the first attempt at using implantable neurostimulation devices for motor recovery. Epidural cortical stimulation has been used since the early 1990s, initially for pain (Tsubokawa et al., 1991) and then for poststroke motor rehabilitation (Brown et al., 2003, 2006). Despite early promise, this approach ultimately failed to show improvements superior to the control group in randomized controlled clinical trial (Harvey et al., 2009; Plow et al., 2009). While the reasons for the failure of animal to human translation are not well known, it is possible that the variability of stroke volume and location in humans complicated the targeting of epidural leads, thereby limiting their ability to induce the theorized reorganization of perilesional cortex. Furthermore, it is possible that the different orientation of neurons in relation to the dura, due to complex gyral anatomy, may have washed out the effects of cathodic or anodic epidural stimulation (Manola et al., 2005; Holsheimer et al., 2007). We anticipate that stimulation of the dentatothalamocortical pathway will obviate these limitations because it relies on a robust natural pathway with extensive projections to the frontal, prefrontal, and parietal cortices (Dum and Strick, 2003). Hence, stimulation at a single node should elicit perilesional effects regardless of discrete changes in stroke topography, as long as subcortical projections are at least partially preserved. Further, thalamocortical fibers will carry stimuli to the cortex regardless of gyral anatomy. In summary, the present results are encouraging in the rodent model and indicate a strong potential for enhancing perilesional plastic reorganization after focal injuries. Next steps include further optimization of stimulation settings and first-in-man clinical trials.

\section{References}

Aumann TD, Fetz EE (2004) Oscillatory activity in forelimb muscles of behaving monkeys evoked by microstimulation in the cerebellar nuclei. Neurosci Lett 361:106-110. CrossRef Medline

Bailey CH, Giustetto M, Zhu H, Chen M, Kandel ER (2000) A novel function for serotonin-mediated short-term facilitation in aplysia: conversion of a transient, cell-wide homosynaptic hebbian plasticity into a persistent, protein synthesis-independent synapse-specific enhancement. Proc Natl Acad Sci U S A 97:11581-11586. CrossRef Medline

Baker KB, Schuster D, Cooperrider J, Machado AG (2010) Deep brain stimulation of the lateral cerebellar nucleus produces frequency-specific alterations in motor evoked potentials in the rat in vivo. Exp Neurol 226:259-264. CrossRef Medline

Brown JA, Lutsep H, Cramer SC, Weinand M (2003) Motor cortex stimu- lation for enhancement of recovery after stroke: case report. Neurol Res 25:815-818. CrossRef Medline

Brown JA, Lutsep HL, Weinand M, Cramer SC (2006) Motor cortex stimulation for the enhancement of recovery from stroke: a prospective, multicenter safety study. Neurosurgery 58:464-473. CrossRef Medline

Buetefisch C, Heger R, Schicks W, Seitz R, Netz J (2011) Hebbian-type stimulation during robot-assisted training in patients with stroke. Neurorehabil Neural Repair 25:645-655. CrossRef Medline

Dancause N, Barbay S, Frost SB, Plautz EJ, Chen D, Zoubina EV, Stowe AM, Nudo RJ (2005) Extensive cortical rewiring after brain injury. J Neurosci 25:10167-10179. CrossRef Medline

Dimyan MA, Cohen LG (2011) Neuroplasticity in the context of motor rehabilitation after stroke. Nat Rev Neurol 7:76-85. CrossRef Medline

Dum RP, Strick PL (2003) An unfolded map of the cerebellar dentate nucleus and its projections to the cerebral cortex. J Neurophysiol 89:634639. Medline

Gharbawie OA, Gonzalez CL, Williams PT, Kleim JA, Whishaw IQ (2005) Middle cerebral artery (MCA) stroke produces dysfunction in adjacent motor cortex as detected by intracortical microstimulation in rats. Neuroscience 130:601-610. CrossRef Medline

Gharbawie OA, Williams PT, Kolb B, Whishaw IQ (2008) Transient middle cerebral artery occlusion disrupts the forelimb movement representations of rat motor cortex. Eur J Neurosci 28:951-963. CrossRef Medline

Ghosh PS, Machado AG, Deogaonkar M, Ghosh D (2012) Deep brain stimulation in children with dystonia: experience from a tertiary care center. Pediatr Neurosurg 48:146-151. CrossRef Medline

Goodkin HP, Thach WT (2003) Cerebellar control of constrained and unconstrained movements. II. EMG and nuclear activity. J Neurophysiol 89:896-908. Medline

Gustin SM, Peck CC, Cheney LB, Macey PM, Murray GM, Henderson LA (2012) Pain and plasticity: is chronic pain always associated with somatosensory cortex activity and reorganization? J Neurosci 32:14874-14884. CrossRef Medline

Harvey RL, Winstein CJ, Everest Trial G (2009) Design for the everest randomized trial of cortical stimulation and rehabilitation for arm function following stroke. Neurorehabil Neural Repair 23:32-44. CrossRef Medline

Hebb D (1949) The organization of behavior: a neuropsychological theory. New York: Wiley.

Holsheimer J, Nguyen JP, Lefaucheur JP, Manola L (2007) Cathodal, anodal or bifocal stimulation of the motor cortex in the management of chronic pain? Acta Neurochir [Suppl 97]:57-66. Medline

Kiryu-Seo S, Ohno N, Kidd GJ, Komuro H, Trapp BD (2010) Demyelination increases axonal stationary mitochondrial size and the speed of axonal mitochondrial transport. J Neurosci 30:6658-6666. CrossRef Medline

Kleim JA, Pipitone MA, Czerlanis C, Greenough WT (1998) Structural stability within the lateral cerebellar nucleus of the rat following complex motor learning. Neurobiol Learn Mem 69:290-306. CrossRef Medline

Kleim JA, Bruneau R, VandenBerg P, MacDonald E, Mulrooney R, Pocock D (2003) Motor cortex stimulation enhances motor recovery and reduces peri-infarct dysfunction following ischemic insult. Neurol Res 25:789793. CrossRef Medline

Knott G, Marchman H, Wall D, Lich B (2008) Serial section scanning electron microscopy of adult brain tissue using focused ion beam milling. J Neurosci 28:2959-2964. CrossRef Medline

Laxton AW, Lozano AM (2013) Deep brain stimulation for the treatment of Alzheimer disease and dementias. World Neurosurg 80:S28.e1-8. CrossRef Medline

Lim TT, Fernandez HH, Cooper S, Wilson KM, Machado AG (2013) Successful deep brain stimulation surgery with intraoperative magnetic resonance imaging on a difficult neuroacanthocytosis case: case report. Neurosurgery 73:E184-187; discussion E188. CrossRef Medline

Machado A, Baker KB (2012) Upside down crossed cerebellar diaschisis: proposing chronic stimulation of the dentatothalamocortical pathway for post-stroke motor recovery. Front Integr Neurosci 6:20. CrossRef Medline

Machado AG, Baker KB, Schuster D, Butler RS, Rezai A (2009) Chronic electrical stimulation of the contralesional lateral cerebellar nucleus enhances recovery of motor function after cerebral ischemia in rats. Brain Res 1280:107-116. CrossRef Medline

Machado AG, Deogaonkar M, Cooper S (2012a) Deep brain stimulation for 
movement disorders: patient selection and technical options. Cleve Clin J Med 79 [Suppl 2]:S19-S24. CrossRef Medline

Machado A, Fernandez HH, Deogaonkar M (2012b) Deep brain stimulation: what can patients expect from it? Cleve Clin J Med 79:113-120. CrossRef Medline

Machado AG, Cooperrider J, Furmaga HT, Baker KB, Park HJ, Chen Z, Gale JT (2013) Chronic 30-Hz deep cerebellar stimulation coupled with training enhances post-ischemia motor recovery and peri-infarct synaptophysin expression in rodents. Neurosurgery 73:344-353, discussion 353. CrossRef Medline

Manola L, Roelofsen BH, Holsheimer J, Marani E, Geelen J (2005) Modelling motor cortex stimulation for chronic pain control: electrical potential field, activating functions and responses of simple nerve fibre models. Med Biol Eng Comput 43:335-343. CrossRef Medline

Mayberg HS, Lozano AM, Voon V, McNeely HE, Seminowicz D, Hamani C, Schwalb JM, Kennedy SH (2005) Deep brain stimulation for treatmentresistant depression. Neuron 45:651-660. CrossRef Medline

Miura K, Tsubo Y, Okada M, Fukai T (2007) Balanced excitatory and inhibitory inputs to cortical neurons decouple firing irregularity from rate modulations. J Neurosci 27:13802-13812. CrossRef Medline

Nicoll RA, Roche KW (2013) Long-term potentiation: peeling the onion. Neuropharmacology 74:18-22. CrossRef Medline

Nudo RJ, Wise BM, SiFuentes F, Milliken GW (1996) Neural substrates for the effects of rehabilitative training on motor recovery after ischemic infarct.[see comment]. Science 272:1791-1794. CrossRef Medline

Pagnussat AS, Simao F, Anastacio JR, Mestriner RG, Michaelsen SM, Castro CC, Salbego C, Netto CA (2012) Effects of skilled and unskilled training on functional recovery and brain plasticity after focal ischemia in adult rats. Brain Res 1486:53-61. CrossRef Medline

Park HJ, Machado AG, Cooperrider J, Truong-Furmaga H, Johnson M, Krishna V, Chen Z, Gale JT (2013) Semi-automated method for estimating lesion volumes. J Neurosci Methods 213:76-83. CrossRef Medline

Paxinos G, Watson C (1998) The rat brain in stereotaxic coordinates, Ed 4. San Diego, CA: Academic.

Plow EB, Carey JR, Nudo RJ, Pascual-Leone A (2009) Invasive cortical stimulation to promote recovery of function after stroke: a critical appraisal. Stroke 40:1926-1931. CrossRef Medline

Plow EB, Malone DA Jr, Machado A (2013) Deep brain stimulation of the ventral striatum/anterior limb of the internal capsule in thalamic pain syndrome: study protocol for a pilot randomized controlled trial. Trials 14:241. CrossRef Medline

Schiff ND, Giacino JT, Kalmar K, Victor JD, Baker K, Gerber M, Fritz B, Eisenberg B, Biondi T, O'Connor J, Kobylarz EJ, Farris S, Machado A, McCagg C, Plum F, Fins JJ, Rezai AR (2007) Behavioural improvements with thalamic stimulation after severe traumatic brain injury. Nature 448 : 600-603. CrossRef Medline

Sjöberg RL, Blomstedt P (2011) The psychological neuroscience of depression: implications for understanding effects of deep brain stimulation. Scand J Psychol 52:411-419. CrossRef Medline

Steiner P, Higley MJ, Xu W, Czervionke BL, Malenka RC, Sabatini BL (2008) Destabilization of the postsynaptic density by PSD-95 serine 73 phosphorylation inhibits spine growth and synaptic plasticity. Neuron 60 : 788-802. CrossRef Medline

Takasawa M, Watanabe M, Yamamoto S, Hoshi T, Sasaki T, Hashikawa K, Matsumoto M, Kinoshita N (2002) Prognostic value of subacute crossed cerebellar diaschisis: single-photon emission CT study in patients with middle cerebral artery territory infarct. AJNR 23:189-193. Medline

Tennant KA, Adkins DL, Donlan NA, Asay AL, Thomas N, Kleim JA, Jones TA (2011) The organization of the forelimb representation of the C57BL/6 mouse motor cortex as defined by intracortical microstimulation and cytoarchitecture. Cereb Cortex 21:865-876. CrossRef Medline

Thach WT (1970) Discharge of cerebellar neurons related to two maintained postures and two prompt movements. II. Purkinje cell output and input. J Neurophysiol 33:537-547. Medline

Tsubo Y, Isomura Y, Fukai T (2012) Power-law inter-spike interval distributions infer a conditional maximization of entropy in cortical neurons. PLoS Comput Biol 8:e1002461. CrossRef Medline

Tsubokawa T, Katayama Y, Yamamoto T, Hirayama T, Koyama S (1991) Chronic motor cortex stimulation for the treatment of central pain. Acta Neurochir [Suppl 52]:12 137-139. Medline

Voss HU, Schiff ND (2009) MRI of neuronal network structure, function, and plasticity. Prog Brain Res 175:483-496. CrossRef Medline

Windle V, Szymanska A, Granter-Button S, White C, Buist R, Peeling J, Corbett D (2006) An analysis of four different methods of producing focal cerebral ischemia with endothelin-1 in the rat. Exp Neurol 201:324 334. CrossRef Medline

Yamamoto T, Katayama Y, Kobayashi K, Oshima H, Fukaya C, Tsubokawa T (2010) Deep brain stimulation for the treatment of vegetative state. Eur J Neurosci 32:1145-1151. CrossRef Medline 